Synthesis, part of a Special Feature on Long-term Vulnerability and Transformation

\title{
Synthesis: Vulnerability, Traps, and Transformations-Long-term Perspectives from Archaeology
}

\author{
$\underline{\text { Michael Schoon }}^{1}, \underline{\text { Christo Fabricius }}^{2}, \underline{\text { John M. Anderies }}^{1}$, and Margaret Nelson $^{1}$
}

\begin{abstract}
In this synthesis, we hope to accomplish two things: 1) reflect on how the analysis of the new archaeological cases presented in this special feature adds to previous case studies by revisiting a set of propositions reported in a 2006 special feature, and 2) reflect on four main ideas that are more specific to the archaeological cases: i) societal choices are influenced by robustness-vulnerability trade-offs, ii) there is interplay between robustness-vulnerability trade-offs and robustness-performance trade-offs, iii) societies often get locked in to particular strategies, and iv) multiple positive feedbacks escalate the perceived cost of societal change. We then discuss whether these lock-in traps can be prevented or whether the risks associated with them can be mitigated. We conclude by highlighting how these long-term historical studies can help us to understand current society, societal practices, and the nexus between ecology and society.
\end{abstract}

Key Words: archaeology; robustness; trade-offs; transformation; vulnerability

\section{INTRODUCTION}

One of the challenges faced in the development of a broad, interdisciplinary, synthetic theory of the dynamics of social-ecological systems (SESs) is confronting the theory with data. Each data point is a complete social-ecological system. As such, it is very difficult, if not impossible, to conduct controlled experiments. One alternative is to confront the theory with multiple, qualitative case studies. Although such case studies cannot be used to formally validate the theory, they can be used to identify broad drivers, characterize relationships among system components, and relate these to particular outcomes and system characteristics that can then be compared with theoretical predictions. An example of this approach in the context of resilience theory is a special feature of Ecology and Society that appeared in 2006. This special feature used 15 contemporary case studies to critically assess the then state of the art in resilience theory and to explore how to manage for resilience in complex social-ecological systems and move beyond traditional command and control management structures.
However, these 15 case studies were limited in their capacity to address one key aspect of resilience theory: the long-term evolution of SESs (over centuries) through adaptive cycles of change. The long-term studies that are the focus of this special feature shed light on factors that affect how societies organize around the resource systems on which they rely, and provide, a posteriori, insights on how they may cope with uncertainty and change. The archaeological cases discussed in this special feature provide long-term empirical studies needed to gain insight regarding how societies may move through the adaptive cycle over time frames far longer than conventional resilience and vulnerability studies.

Further, by looking across multiple temporal scales in assessing adaptations and transformations, researchers gain insight into how what is perceived as a transformative event from a local or short-term perspective may appear as a more gradual adaptation at a larger scale. Conversely, a slowly dwindling population may appear stable to an observer within the population, but may result in a transformative shift at a societal level when viewed on a larger time scale. Likewise, a shift in the 
geographical scale may change perspectives of what constitutes adaptation or transformation. We see the larger temporal scale of the cases in this special feature as providing insight into the continuum of adaptation and transformation. Specifically, the perception of where along the continuum a change occurs depends on the scale at which the change is examined. Whereas the initial creation and build-up of social and physical infrastructure can help people thrive in a wide variety of environments, these longterm studies show how slow accretion of rigidity in societal infrastructure may eventually lead to relatively rapid transformation. The capacity to adapt to novel change and shocks is compromised by commitments to specific forms of social and physical infrastructure. Physical infrastructure strongly conditions the nature of interactions between people and the environment and among people. Social infrastructure, in concert with physical infrastructure, conditions the structure of human relations and can increase connectedness of social networks. Beyond a critical threshold, both may lead to institutional rigidity and "stickiness." Commitment to specific forms of infrastructure generates inertia that is maintained through a prolonged K-phase in the adaptive cycle. In effect, this can be viewed as a form of path dependency from which change is difficult. Along with another key slow driver, increases in human population density, this inertia may severely constrain the capacity of societies to respond to rapid change, precipitating rapid and dramatic transformations.

The articles throughout this special feature highlight the subtle interplay among social and physical infrastructure, stability, and adaptation or transformation. The stability domains created by the slow processes represented in the cases are typically associated with the suppression of particular classes of variation, e.g., interannual fluctuations in resource availability, and social domains, e.g., power relations, or equality. Construction of infrastructure to ameliorate variability in some conditions "necessarily" creates vulnerabilities to other conditions or other classes of shocks. That is, societies face robustness-vulnerability trade-offs in their choices about investment in infrastructure. Over the long term, these trade-offs can be viewed as shifting vulnerabilities between time scales, favoring the present over the long term, or between groups of people, that is, insiders as opposed to others, or between classes.
Here, we hope to accomplish two things: 1) reflect on how the analysis of the new archaeological cases presented in this special feature adds to previous case studies by revisiting a set of propositions reported in the 2006 special feature, and 2) reflect on four main ideas that are more specific to the archaeological cases: i) societal choices are influenced by robustness-vulnerability trade-offs, ii) there is interplay between robustnessvulnerability trade-offs and robustness-performance trade-offs, iii) societies often get locked in to particular strategies, and iv) multiple positive feedbacks escalate the perceived cost of societal change. We then discuss whether these lock-in traps can be prevented or whether the risks associated with them can be mitigated. We conclude by highlighting how these long-term historical studies can help us to understand current society, societal practices, and the nexus between ecology and society.

\section{TESTING PROPOSITIONS OF MANAGEMENT FOR RESILIENCE}

In 2006, a special feature of Ecology and Society was published that critically assessed resilience theory against 15 contemporary case studies and attempted to extract lessons about how to manage for resilience in complex social-ecological systems that move beyond traditional command and control management structures. Anderies et al. (2006) synthesized the findings of 15 case studies exploring resilience in social-ecological systems, and concluded with 10 propositions for managing resilience. Using the archaeological cases, we explore whether there is evidence for these propositions in practice and, if so, their implications over very large time scales. The case studies in the current special feature did not set out specifically to test these propositions, and in some cases the archaeological record sheds no light on particular points (e.g., points 7, "understanding underlying mental models" or 9, "recognizing windows for transformation" that are more relevant for managers that actively confront challenges of managing for resilience. In what follows, we step through each of the propositions that our cases appraise.

1. Manage for as many potential configurations of SESs as possible. The idea of managing for multiple potential configurations is useful at the scale of a single resource system, but 
probably does not make sense at the scale of a society. Management, whether conscious or not, at the level of the society in the cases in this special feature relates to agricultural strategies and migration. Anderies and Hegmon (2011) show how movement between three different regions with different productivity levels can increase the resilience of a SES in the face of variability in either population changes, resource availability, or a combination of social-ecological changes. In this case, the potential configurations relate to distribution of resource abundance in three regions annually. Migration allows for populations to adjust resource-use intensity to these potential configurations. However, there are issues with how costs of migration strategies are borne depending on particular resource configurations. This emphasizes the point that increasing resilience or robustness can be costly (for some).

2. Manage at multiple scales as much as possible. The papers in the special feature provide evidence suggesting that societies, whether consciously or not, manage at multiple scales. Whereas the proposition finds support with respect to migration to and from densely populated centers and the hinterlands (Anderies and Hegmon 2011) and the distribution of resources through trade (Janssen 2011), other studies indicate the problems with failure to manage across multiple scales. Nelson et al. (2011b) identify cases where the minimization of disturbances at one scale may come at the expense of increased vulnerability to disturbances at another scale. This case illustrates real limits to the capacity to manage at multiple scales. Cross-scale institutions for trade, such as reciprocity or relation building, may build adaptive capacity through innovation and ideas from narrower or broader scales.

3. Attend to slow variables. Spielmann et al. (2011) show how people responded to the slow variable of long-term change in precipitation by gradually, that is, over centuries, shifting to permanently watered areas. This shift ultimately meant giving up a flexible strategy of frequent movement of residences and field areas that had been used for centuries to adjust to climate variability. This centuries-long solution of mobility was replaced by an adjustment to slow processes. In this case, attention to slow variables may have negative consequences by reducing the capacity of the system to adjust to fast variables. This again emphasizes the importance of trade-offs, suggesting that attending to slow variables is not sufficient. This statement might be extended to read: attend to multiple temporal scales, paying attention to trade-offs induced by various responses to particular temporal scales. Additionally, several of the papers note how social and physical infrastructure slowly build up over time in response to fast variables such as small-scale seasonal flooding in irrigation-fed agriculture and, in the process, increase vulnerability to longer term changes in slow variables, like the climatic systems (Spielmann et al. 2011, Nelson et al. 2011b). Janssen (2011) also examines the interaction of long-term population dynamics, shortterm climatic variability, and the storage, sharing, and exchange of resources among spatially disparate groups. In these last examples, the cases point to a loss of resilience because of inattention or lack of understanding of the slow variables.

4. Manage for diversity. Nelson et al. (2011b) illustrate well how simplifying production for increased efficiency (Anderies et al. 2006) can contribute over the long term to dramatic transformation. The Hohokam efficient irrigation system ultimately collapsed along with social institutions, people died, and others left the region because the system became rigid and specialized on canal irrigation. The contrasting Zuni system of diverse, shifting farming locales and strategies persisted through climate changes and social changes in the region.

Nelson et al. (2011b) examine why people might reduce social diversity to increase the ease of decision making in small-group settings. They show that this shift to reduced diversity in material expressions of social relations is associated with dramatic transformations in some contexts, supporting this principle but also noting some of the reasons for reductions in social diversity.

5. Accept that maintaining resilience incurs costs. Nelson et al. (2011b), in comparing the 
Hohokam, Mimbres, and Zuni, explore tradeoffs between short-term efficiency and longterm persistence. The Hohokam system, which was heavily capitalized toward efficiency for improved productivity, collapsed most dramatically. The long-term study of this Hohokam case does show that the costs of investing in this infrastructure were, for several centuries, ameliorated through effective social networks that distributed resources widely. However, when these networks were broken, the system experienced a slow, difficult decline. The authors illustrate that the costs of any strategy are context dependent. As mentioned above, Anderies and Hegmon (2011) illustrate that maintaining resilience to climate shocks at various scales usually incurs costs for at least some groups in the system. Managing tradeoffs requires attention to the specifics of each context in both short and long time frames.

6. Embrace adaptive governance. Anderies and Hegmon (2011) and Nelson et al. (2011a) examine how a flexible social system, in this case one that supports frequent movement and reorganization of people across landscapes and villages, provides the backdrop to allow solutions to difficulties. In the Mimbres case, people adjusted to population-resource challenges, climate change, and social tensions by reorganizing, rather than through short-term solutions of capitalizing their investments in land and infrastructure. The social flexibility of the system made this possible.

7. Recognize that vulnerability cannot be eliminated. Both the agent-based modeling of Janssen (2011) and the dynamic modeling of Anderies and Hegmon (2011), as well as the empirical studies presented here, strongly support the idea that robustness-vulnerability trade-offs exist and are important. In each case, societies made decisions, both implicitly and explicitly, to shift vulnerabilities temporally or spatially. In no instances were vulnerabilities wholly removed or displaced, but were shifted through societal choices.

Building on this final point about the conservation of vulnerability, we turn to the first of the four main messages that emerged from the case studies in this special feature.

\section{SOCIETAL CHOICES AND ROBUSTNESS- VULNERABILITY TRADE-OFFS}

The capacity of social configurations to cope with change depends on the magnitude and abruptness of environmental and social change and, importantly, on the decisions taken or "responses" (sensu Millennium Ecosystem Assessment 2005) to such change. This special feature considers the following strategies for reducing vulnerability: 1) migration (Anderies and Hegmon 2011, Spielmann et al. 2011), 2) social networking and trading (Janssen 2011, Nelson et al. 2011b), 3) engaging in a diversity of social practices (Nelson et al. 2011a), reciprocity by sharing resources with others (Spielmann et al. 2011), and 4) conserving and storing food and water resources (Anderies and Hegmon 2011, Janssen 2011, Spielmann et al. 2011). However, our case studies show that, in hindsight, prehistoric societies sometimes made choices that increased rather than decreased their vulnerability. Note, robustness-vulnerability tradeoffs are very subtle, particularly with changes in slow variables. It is difficult for people in any society to detect the new vulnerabilities they are creating until they experience them. At that point, transformation is already underway and people may be unable to respond. Further, this observation calls into question whether either past or current decision-making procedures can effectively make sustainability decisions on large time scales, let alone on intergenerational time scales. However, understanding long-term trade-offs and processes can enhance our ability for decision making that impacts long-term resilience.

\section{THE INFLUENCE OF ROBUSTNESS- PERFORMANCE TRADE-OFFS ON ROBUSTNESS-VULNERABILITY TRADE- OFFS}

Individuals and social groups make choices, in part, on the basis of a trade-off between the perceived social costs of a decision and the perceived material benefits derived from it. The perceived social cost of a decision or choice, i.e., the "sacrifices" made by either exerting additional energy, incurring additional risks, or forfeiting existing options and opportunities, are weighed up against the perceived benefits, i.e., the immediate advantages for human well-being. There are always fundamental tradeoffs between robustness and performance. These are much easier to see than robustness-vulnerability 
trade-offs. However, there are always winners and losers, and the social problem of distributing benefits and costs is significant. Thus, people face, at a minimum, a two-level problem of navigating robustness-performance trade-offs and the more subtle, frequently imperceptible, associated robustness-vulnerability trade-offs.

Not only does the navigation of this two-level problem directly confront a more easily perceived trade-off between robustness and performance with the frequently less understood trade-off between robustness and vulnerability, but it also faces two further challenges. First, the time scales relevant to these two trade-offs pit the short-term and rapid decision making regarding performance against the longer term vulnerability concerns that are often governed by slow-changing variables. The second issue surfaces when building robustness to relevant shocks runs counter to the immediate desires of society. Decisions to migrate (as in Anderies and Hegmon 2011), to trade (Janssen 2011) or to nucleate (Nelson et al. 2011a) may all be responses to system shocks and perceived vulnerabilities, or they may be decisions made for wholly different reasons such as individual or societal values and beliefs. Societies continually face the challenge of minimizing appropriate vulnerabilities and the balancing of trade-offs of both performance and vulnerability.

\section{LOCK-IN AND PERSISTENCE IN THE K- PHASE OF THE ADAPTIVE CYCLE}

Each of the case studies in the special feature illustrates that, in certain contexts, strategies that inevitably reduce resilience become captivating despite the obvious costs and risks associated with them, that is, a lock-in situation (Scheffer and Westley 2007) with persistence of the K-phase of the adaptive cycle. This research highlights some interesting questions worthy of further research:

1. Why are some societies prepared to remain in the trap of aggregation and high population density, inevitably leading to malnutrition, disease, and social conflict when they have other options? Why do others escape such traps?

2. When does the K-phase of the adaptive cycle coincide with channelization of thoughts and actions, path dependency, and lock-in that result in collapse, and what makes it possible for others to adapt before collapse and dramatic transformation?

3. How do lessons learned over the long term through archaeological research inform current trends of social-ecological systems in the K-phase, for example, increasing urbanization, continued dependence on fossil-fuel based economies, the build-up of physical and social infrastructure?

\section{FEEDBACK INFLUENCING THE PERCEIVED COST OF CHANGE}

The five studies all note, to varying degrees, that the perceived cost of change escalates as a result of positive feedbacks related to four key factors: 1) rigidity and conformity, an aspect of social infrastructure, 2) population size, 3) investment in, and perceptions of, physical infrastructure, and 4) perceptions of external threats on perceived costs of change. At some point, a threshold is reached and people or groups no longer perceive that they have the liberty of choice; social, ecological, economic, or political circumstances force them into a limited suite of options. Scheffer and Westley (2007) argue that societies with high levels of conformity or peer pressure prefer inaction, used here in the sense of the inability to change/adapt. In such contexts, the perceived gains have to be extremely high before a rapid shift, from inaction to action takes over. This is not unlike a regime shift, sensu Walker and Meyers (2004). The social costs of inaction escalate rapidly as time passes. This results from increased investments in time, energy, psychological "buyin," and material resources in the "status quo" over time. The positive feedbacks result in a rapidly strengthening lock-in or trap from which "escape" becomes increasingly difficult.

Here, we discuss each of the positive feedbacks in the context of our case studies.

1. Rigidity and conformity in social infrastructure. Archaeological research shows that two factors were closely associated with rapid and severe transformations in these prehistoric American societies: 1) limitations in social and materials diversity, and 2) investments in infrastructure that limited 
options. Nelson et al.(2011a) find that, in some cases, low material diversity, such as of pottery ware, is indicative of conforming behavior preceding dramatic transformations, and postulate, along with theorists (Folke 2006), that diversity can increase resilience. Nelson et al. (2011b) show that rigidly designed, "heavy" canal systems of the Hohokam contributed to conditions that precipitated a catastrophic collapse, whereas the Zuni, who maintained a diverse suite of farming practices that were modified with changes in climate conditions, experienced a more gradual transformation. It is worth noting that the Hohokam canal system was considerably more efficient than the diversity of Zuni farming practices for boosting the productivity of arable land, but commitment to the canal system contributed to the catastrophic social and demographic collapse of the Hohokam.

2. Population size. Large populations were associated with increased settlement size (Anderies and Hegmon 2011), increased investments in infrastructure such as canals and villages (Anderies and Hegmon 2011, Nelson et al. 2011b), reduced social diversity as reflected by pottery styles (Nelson et al. 2011a), heavier reliance on agriculture because of the depletion of natural wildlife and vegetation cover (Janssen 2011, Spielmann et al. 2011), and land shortages, resulting in a perceived increase in the value of land (Nelson et al. 2011b). These factors increased the costs of resilience-enhancing strategies such as dispersal (Spielmann et al. 2011), migration (Janssen 2011), and diversification. Population could be viewed as one of the "ultimate drivers" of vulnerability (Millenium Ecosystem Assessment 2005).

3. Investment in and perceptions of physical infrastructure. In one of the prehistoric sequences examined, concentrated infrastructure in the form of large villages in the Mimbres Valley acted as attractors that drew people from other areas, leading to elevated population levels and depletion of soil and biological resources (Anderies and Hegmon). Residential infrastructure and structures for water storage and irrigation can increase water security for a given population, but the trade-off is that population often increases (Nelson et al. 2011b). This trade-off is exacerbated as people prolong their stay for cultural and aesthetic reasons, further exploiting the remaining resources (Anderies and Hegmon). Investments in infrastructure that increase attachment to place (Nelson et al. 2011b), aggregation, and densification can increase rigidity (Hegmon et al. 2008). In turn, this increase in rigidity is one of the primary factors preceding collapse through conflict, large scale emigration, and mortalities. This prolonged $\mathrm{K}$-phase, as noted earlier, is associated with an increased investment of energy and time to both construct and maintain infrastructure, thereby skewing the trade-off in favor of strategies that reduce resilience. Another consequence of infrastructure investment and the associated aggregation is the neglect for other coping strategies such as migration and trade networks (Nelson et al. 2011a). This increases the perception of risk or loss associated with change, further increasing the cost of change. Societies such as the Zuni that did not invest in expensive and long-lasting infrastructure for farming, and maintained extensive social networks and distant linkages experienced less dramatic transformations than those who with greater investments in irrigation infrastructure (Nelson et al. 2011a).

4. Threat perceptions. Security, including personal safety, security of access to resources and security from disasters, is one of the core components of human well-being (Millenium Ecosystem Assessment 2005). When this is threatened, people become more inward looking and less willing to adopt resilience-enhancing strategies because of the high perceived costs. They tend to aggregate rather than disperse, opt for homogeneous rather than diverse cultural practices (Nelson et al. 2011a), and keep food and resources rather than sharing them with other groups (Spielmann et al. 2011). The challenge that emerges from the studies in this special feature is that the proximity of crises is often remote and governed by difficult to perceive, slow variables. At the same time, the speed of change to infrastructure when confronted by many of these perceived threats 
often requires more time and investment than is available once such threats are observed.

\section{CAN LOCK-IN TRAPS BE PREVENTED?}

Some prehistoric societies experienced less severe consequences of underlying fundamental robustnessvulnerability trade-offs than did others, such as the Zuni contrasted with the Hohokam (Nelson et al. $2011 b$ ). What did the Zuni, knowingly or unknowingly, do to avoid such severe consequences? A multitude of adaptation strategies, including migration, exchange, resource usage patterns, storage, irrigation, and others, and a variety of institutional arrangements have led to a diversity of pathways to attempt to mitigate long-term vulnerability. The analysis of these long-term case studies suggests some common features of systems that at once increase their resilience and avoid lockin traps.

In many cases, the role of diversity and flexibility of both social and physical infrastructure in increasing or building resilience emerges as a key to mitigating against lock-in traps. The cases presented identify how social diversity encourages novelty and the ability to adapt out of a prolonged K-phase before collapse. Examples show how flexible institutional design and a diversity of institutional arrangements can help prevent lock-in traps, how task specialization can create a diversity of viewpoints and ideas, and how disaggregation from high-density areas to more sparsely populated sites facilitates experimentation and a diversity of approaches for avoiding rigidity traps. Likewise, such disaggregation also provides a source of recovery for unsuccessful experimentation.

Managing across scales is also a frequently recurring theme for avoiding lock-in traps. This may occur through cross-scale institutions for trade, such as reciprocity and relation-building, which may reinvigorate a SES at one scale through innovation from narrower or broader scales. Similarly, vulnerability at one scale or locality may be reduced through migration and trade across a broader scale, shifting vulnerabilities spatially and temporally. This notion of shifting vulnerabilities also arises in the idea of using frequent small disturbances to "force" regular reorganization and, in the process, reducing vulnerability to less frequent, higher amplitude disturbances. This parallels Schumpeter's ideas of periodic shake-ups and "creative destruction" for development. Schumpeterian creative destruction also links back to the ideas of radical experimentation and innovation as a necessary part of building resilience.

\section{CONCLUSIONS}

The contributors to this special feature all emphasize the goal of improving societal capacity for sustainability. They emphasize the value of resilience thinking and the importance of long-term empirical studies of resilience, robustness, and vulnerability in coupled social-ecological systems, particularly with social and/or institutional data, as a means to achieve this objective. By resilience thinking, the authors stress taking a holistic, forward-looking perspective (sensu Walker and Salt 2006). Echoing the lessons empirically exhibited in the cases of this special feature, Berkes (2007) highlights the importance of experimentation and learning, ecological and social diversity, and opportunities for self-organization as fundamental to achieving system resilience.

The studies presented here highlight how long-term historical studies can help us to understand current society, societal practices, and the social-ecological interface. Building and adapting today's systems for long-term social-ecological sustainability requires learning from past successes and failures in longenduring systems and being able to more accurately diagnose, experiment with solutions, and take action based on new learning.

Responses to this article can be read online at: http://www.ecologyandsociety.org/voll6/iss2/art24/ responses/

\section{LITERATURE CITED}

Anderies, J. M., B. H. Walker, and A. P. Kinzig. 2006. Fifteen weddings and a funeral: case studies and resilience-based management. Ecology and Society 11(1): 21. [online] URL: http://www.ecolog yandsociety.org/vol11/iss1/art21/.

Anderies, J. M., and M. Hegmon. 2011. Robustness and resilience across scales: migration and resource 
degradation in the prehistoric US southwest. Ecology and Society: 16(2): 22. [online] URL: http ://www.ecologyandsociety.org/vol16/iss2/art22/.

Berkes, F. 2007. Understanding uncertainty and reducing vulnerability: lessons from resilience thinking. Natural Hazards 41:283-295.

Folke, C. 2006. Resilience: rhe emergence of a perspective for social-ecological systems analyses. Global Environmental Change 16:253-267.

Hegmon, M., M. Peeples, A. Kinzig, S. Kulow, C. M. Meegan, and M. C. Nelson. 2008. Social transformation and its human costs in the Prehispanic US Southwest. American Anthropologist 110:313-324.

Janssen, M. A. 2011. Population aggregation in ancient arid environments Ecology and Society 15 (2): 19. [online] URL: http://www.ecologyandsociety. org/vol15/iss2/art19/.

Millenium Ecosystem Assessment. 2005. Ecosystems and human well-being: synthesis. Island Press, Washington, D.C., USA.

Nelson, M., M. Hegmon, S. Kulow, M. Peeples, K. Kintigh, and A. Kinzig. 2011a. Resisting diversity: a long-term archaeological study. Ecology and Society 16(1): 25. [online] URL: http://www.ecolog yandsociety.org/vol16/iss 1/art25/.

Nelson, M., K. Kintigh, D. Abbott, and J. Anderies. $2011 \mathrm{~b}$. The cross-scale interplay between social and biophysical context and the vulnerability of irrigation-dependent societies: archaeology's longterm perspective.Ecology and Society 15(3): 31.[online] URL: http://www.ecologyandsociety.org/ vol15/iss3/art31/.

Scheffer, M., and F. R. Westley. 2007. The evolutionary basis of rigidity: locks in cells, minds, and society. Ecology and Society 12(2): 36. [online] URL: http://www.ecologyandsociety.org/vol12/iss2/ $\underline{\operatorname{art36}}$.

Schumpeter, J. A. 1942. Capitalism, socialism, and democracy. Harper and Brothers, New York, New York, USA.

Spielmann, K., M. Nelson, S. Ingram, and M. Peeples. 2011. Sustainable small-scale agriculture in semi-arid environments.Ecology and Society 16
(1): 26. [online] URL: http://www.ecologyandsociety. org/vol16/iss1/art26/.

Walker, B., and J. A. Meyers. 2004. Thresholds in ecological and social-ecological systems: a developing database. Ecology and Society 9(2): 3 [online] URL: http://www.ecologyandsociety.org/vol9/ iss2/art3.

Walker, B. H., and D. Salt. 2006. Resilience thinking: sustaining ecosystems and people in a changing world. Island Press, Washington, D.C., USA. 